\title{
QUALIDADE PÓS-COLHEITA DA PÊRA (Pyrus communis L.) CULTIVAR CARRICK SUBMETIDA A DIFERENTES CONDIÇÕES DE ARMAZENAMENTO ${ }^{1}$
}

\author{
ENILTON FICK COUTINHO², MARCELO BARBOSA MALGARIM ${ }^{3}$, EDSON LUIZ DE SOUZA ${ }^{4}$, \\ ROSA DE OLIVEIRA TREPTOW
}

\begin{abstract}
RESUMO - As pêras européias não alcançam a maturidade de consumo na planta, sendo amadurecidas após a colheita, mediante armazenamento. O presente trabalho objetivou avaliar a qualidade pós-colheita de pêras cv. Carrick sob diferentes condições de armazenamento. As frutas foram armazenadas à temperatura de $0 \pm 0,5^{\circ} \mathrm{C}$ e umidade relativa (UR) de $90-95 \%$ e, para simulação da comercialização, temperatura de $20^{\circ} \pm 1^{\circ} \mathrm{C}$ e UR de 75 $80 \%$. As frutas foram submetidas aos tratamentos: T1) 30 dias a $0^{\circ} \mathrm{C}$; T2) 28 dias a $0^{\circ} \mathrm{C}+2$ dias a $20^{\circ} \mathrm{C}$; T3) 26 dias a $0^{\circ} \mathrm{C}+4$ dias a $20^{\circ} \mathrm{C}$; T4) 24 dias a $0^{\circ} \mathrm{C}+6$ dias a $20^{\circ} \mathrm{C}$. Após 30 dias, foram analisadas as seguintes variáveis: sólidos solúveis totais (SST); acidez titulável (AT); relação SST/AT; cor; firmeza de polpa e ocorrência de podridão. Foram avaliadas, ainda, as características sensoriais de sabor e textura, com equipe treinada. Os valores de firmeza da polpa variaram de 15,51 a 3,70 libras. As cores amarelo e vermelho da epiderme tornaram-se mais intensas nos tratamentos T3 e T4; a AT e os SST variaram de 0,39 a $0,32 \%$ e 13,4 a $13,87^{\circ}$ Brix, respectivamente. Os tratamentos T3 e T4 apresentaram melhores características de sabor e qualidade geral, sendo as frutas classificadas de boa a ótima qualidade. As frutas armazenadas sob refrigeração por 24 e 26 dias, e transferidas por 4 a 6 dias para temperatura de $20^{\circ} \mathrm{C}$ apresentaram melhor qualidade na comercialização e consumo.
\end{abstract}

Termos de Indexação: Pêra, maturação, qualidade, armazenamento, análise sensorial.

\section{POSTHARVEST QUALITY OF PEAR (Pyrus communis L.) CV. CARRICK SUBMITTED TO DIFERENTS STORAGE CONDITIONS}

ABSTRACT - The European pears don't reach the consumption maturity in the plant, being ripened before the consumption, through the storage. The present work aimed to evaluate the post harvest quality of pears cv. Carrick in different periods of cold storage. The fruits were stored at $0^{\circ} \pm 0,5^{\circ} \mathrm{C}$ temperature and relative humidity $(\mathrm{RH})$ of $90-95 \%$, and for simulation of the commercialization in temperature of $20^{\circ} \pm 1^{\circ} \mathrm{C}$ and $\mathrm{RH}$ of $75-80 \%$. The fruits were submitted to the treatments: T1) 30 days of $0{ }^{\circ} \mathrm{C}$; T2) 28 days of $0^{\circ} \mathrm{C}+2$ days to $20^{\circ} \mathrm{C}$; T3) 26 days of $0^{\circ} \mathrm{C}+4$ days at $20^{\circ} \mathrm{C}$; T4) 24 days at $0^{\circ} \mathrm{C}+$ 6 days at $20^{\circ} \mathrm{C}$. After 30 days the following variables were analyzed: total soluble solids (TSS); titratable acidity (TA); TSS/TA ratio; color; flesh firmness and rottenness. It was evaluated the sensorial characteristics of flavor and texture, with trained team. In the flesh firmness the values varied from 15,51 to 3,70 pounds. Coloration of the epidermis, became more intense in the colors yellow and red in the treatments T3 and T4; the values of TA and TSS varied from 0,39 to $0,32 \%$ of malic acid, and 13,4 to $13,87^{\circ}$ Brix respectively. The treatments $\mathrm{T} 3$ and T4 presented better characteristic sensorial of flavor, texture and general quality, being classified the fruits from good to great quality. The fruits, stored under refrigeration for 24 and 26 days and then transferred to an ambient temperature, for 4 to 6 days, showed better quality of the commercialization and consumption.

Index Terms: pear, maturity, quality, storage, sensorial analysis.

\section{INTRODUÇÃO}

A pereira (Pirus communis L.) é uma fruta de clima temperado de grande importância nacional, tendo em vista seu alto consumo, sendo a quarta fruta de clima temperado mais consumida no Brasil, após a maçã e o pêssego (Nakasu e Leite, 1990; Zecca, 1995). No entanto, quando se compara a produção brasileira dessas frutas, é a menos expressiva, o que impõe ao país a condição de segundo maior importador, com cerca de 162 mil toneladas, em 1997 (João et al. 2002; Madail e Reichert, 2002).

No Brasil, o cultivo da pereira de alta qualidade, em escala comercial é pequeno, sendo que pequenas áreas de plantio estão localizadas nos estados do Sul. O plantio de cultivares de baixa qualidade tem favorecido as importações de pêra fresca, principalmente do Chile e Argentina. Para aumentar seu consumo "per capita" que está em torno de $0,5 \mathrm{Kg} /$ ano, o país deverá produzir frutas de qualidade semelhante às importadas.

O tipo de respiração das pêras é climatérica. Durante a maturação, as frutas experimentam um mínimo climatérico que precede uma fase de rápido aumento da atividade respiratória definida como "crise climatérica". Nesta fase, a fruta passa por profundas e rápidas modificações bioquímicas como a hidrólise do amido, o aumento dos açúcares, a solubilização da protopectina e a modificação dos pigmentos da pele, dentre outras (Porrit, 1964).

As pêras européias não alcançam a maturidade para consumo na planta, requerendo, em determinados casos, tratamentos pós-colheita especiais. Quando as pêras européias permanecem na árvore, desenvolvem uma textura pobre, falta de suco e ausência do sabor típico da cultivar. De modo geral, devem ser colhidas na maturidade fisiológica, geralmente muito firmes, sendo amadurecidas antes do consumo, mediante o armazenamento refrigerado de -1 a $0^{\circ} \mathrm{C}$ e $90-95 \%$ de umidade relativa (UR). Logo após o armazenamento em frio, as pêras completam seu amadurecimento em ambiente com temperaturas entre 15 e $21^{\circ} \mathrm{C}$ e $80-85 \%$ de UR (Cantillano, 1987).

O presente trabalho teve por objetivo avaliar a qualidade póscolheita de pêras cv. Carrick sob diferentes condições de armazenamento.

\section{MATERIAL EMÉTODOS}

O experimento realizou-se com frutas de tamanho médio com peso em torno de $180 \mathrm{~g}$, da safra 2000/01, utilizando as câmaras frigoríficas e laboratórios de Pós-colheita e Tecnologia de Alimentos da Embrapa Clima Temperado, Pelotas, RS, Brasil.

As pêras cultivar Carrick procederam de pomar localizado nesse centro de pesquisa, onde, depois de colhidas, foram classificadas e selecionadas com relação ao ponto de colheita, coloração marrom esverdeada da película e presença de manchas avermelhadas na parte exposta ao sol (Ribeiro et al, 1991). As frutas foram embaladas em caixas de $5 \mathrm{~kg}$ com dimensões de 0,45 x 0,30 x $0,15 \mathrm{~m}$ (comprimento, largura e altura, respectivamente) previamente sanitizadas e armazenadas em câmara fria de $25 \mathrm{~m}^{3}\left(0 \pm 0,5^{\circ} \mathrm{C}\right.$ e $90-95 \%$ de UR), para fins de simulação das condições de comercialização, com posterior transferência para

\footnotetext{
${ }^{1}$ (Trabalho 030/2003). Recebido: 16/12/2002. Aceito para publicação: 31/10/2003.

${ }^{2}$ Eng. Agr., Dr., Pesquisador, EMBRAPA-CPACT, enilton@cpact.embrapa.br, Fone: 0532758146.

${ }^{3}$ Eng. Agr., MSc., Doutorando em Fruticultura de Clima Temperado UFPeI, malgarim@ufpel.tche.br, Fone: 0532758189.

${ }^{4}$ Eng. Agr., MSc., Ciência e Tecnologia Agroindustrial - DCTA, UFPeI, Cx.P. 394, CEP 96001-970, Pelota/RS

${ }^{5}$ Economista Doméstica, MSc., UFPel, Cx. P. 394, CEP 96001-970, Pelotas/RS.
} 
temperatura ambiente $\left(20 \pm 1^{\circ} \mathrm{C}\right.$ e $65-70 \%$ de UR). Os tratamentos testados foram: T1) 30 dias a $0^{\circ} \mathrm{C}$; T2) 28 dias a $0^{\circ} \mathrm{C}+2$ dias a $20^{\circ} \mathrm{C}$; T3) 26 dias a $0^{\circ} \mathrm{C}+4$ dias a $\left.20^{\circ} \mathrm{C} ; \mathrm{T} 4\right) 24$ dias a $0^{\circ} \mathrm{C}+6$ dias a $20^{\circ} \mathrm{C}$.

Por ocasião da colheita e após 30 dias de armazenamento foram analisadas variáveis físico-químicas e químicas. Teor de sólidos solúveis totais (SST) foi expresso em ${ }^{\circ}$ Brix; acidez titulável (AT), em \% de ácido málico foi determinada segundo metodologia do Instituto Adolfo Lutz (1985); relação SST/AT; ocorrência de podridões expressa em porcentagem; a avaliação da cor foi realizada com colorímetro Minolta CR-300 (fonte de luz D 65) e firmeza de polpa, determinada utilizando-se um penetrômetro manual da marca McCornick FT 327, com ponteira de $5 / 16$ polegadas e resultado expresso em libras.

A avaliação sensorial foi realizada por 11 julgadores treinados, através de métodos discriminativos (Lawless e Haymann, 1998). As características analisadas foram: a) aparência: compreendendo os atributos de cor da epiderme, defeitos e desidratação; b) sabor: incluindo doçura, acidez, sabor característico e sabor estranho; c) textura: firmeza da polpa, suculência e arenosidade e adstringência. Avaliou-se, ainda, a qualidade geral, levando-se em consideração o sabor, a textura e intenção de compra com base na aparência.

Os testes sensoriais foram realizados em cabines individuais, em pratos brancos codificados com três dígitos aleatórios, padronizando-se o tamanho da amostra para avaliação das características de sabor e textura. As características de aparência foram analisadas em uma mesa central no laboratório de avaliação sensorial, com controle de iluminação, estando as frutas colocadas em bandejas plásticas brancas, codificadas. O método empregado foi o Descritivo, teste de avaliação de atributos, segundo Lawless e Haymann (1998). Os dados foram coletados através de fichas individuais, utilizando escalas não estruturadas de $9 \mathrm{~cm}$, cujo extremo esquerdo corresponde a menor intensidade e o direito a maior intensidade dos atributos em análise.

O delineamento estatístico das análises químicas foi o inteiramente casualizado, utilizando-se 10 frutas por tratamento e 3 repetições. Para a comparação de médias usou-se o teste de Duncan. $\mathrm{Na}$ avaliação sensorial, foram empregados blocos casualizados, sendo cada julgador uma repetição. A comparação de médias foi através do teste Tukey, em nível de 5\% de probabilidade.

\section{RESULTADOS E DISCUSSÃO}

Observou-se diminuição progressiva da firmeza da polpa das frutas, a partir da colheita, nos diferentes períodos de armazenamento refrigerado e sob temperatura ambiente (Figura 1). Os frutos que permaneceram 30 dias a $0^{\circ} \mathrm{C}(\mathrm{T} 1)$ e os que permaneceram 28 dias a $0^{\circ} \mathrm{C}$, acrescidos de 2 dias a $20^{\circ} \mathrm{C}$ (T2), não diferiram entre si, quanto à firmeza. Os tratamentos 3 e 4 diferiram entre si e em relação aos demais, registrando-se uma marcante redução nos valores, indicando que a diminuição de dois dias no tempo em câmara e acréscimo de dois dias no tempo de simulação de prateleira causou estas transformações (Figura 1). O mesmo comportamento foi constatado nas frutas submetidas ao tratamento 4, em que foram observados os menores valores de firmeza. Portanto, a firmeza diminuiu com o aumento do tempo sob temperatura ambiente. Resultados semelhantes foram obtidos por Seibert et al (2000), com a cv. Packham's submetidas a dois e oito dias de vida de prateleira em temperatura ambiente.

As pêras européias necessitam de um período de tempo em temperatura ambiente para completar o amadurecimento, caracterizado por perda da firmeza dos tecidos. Segundo Ahmede e Labavith (1970), citado por Seibert et al (2000), a diminuição da firmeza da polpa é devido, basicamente, à dissociação das paredes celulares, com diminuição no grau de polimerização de ácidos urônicos que geralmente é acompanhado de aumento nos teores de pectinas solúveis.

Os valores de cor de superfície $\mathrm{a}^{*}(+\mathrm{a}=$ vermelha $\mathrm{e}-\mathrm{a}=$ verde $)$ e cor de fundo $b^{*}(+b=$ amarelo $\mathrm{e}-\mathrm{b}=\mathrm{azul})$, apresentaram acréscimos com o aumento sob temperatura ambiente, o que significou a evolução da coloração das frutas, respectivamente, vermelha de superfície e amarela de fundo (Tabela 1). Quanto aos valores da luminosidade ou claridade da cor $\mathrm{L}^{*}(0=$ preto e $100=$ branco $)$ apresentaram acréscimo com o aumento do tempo sob temperatura ambiente, significando que a cor das pêras ficou mais clara. No mesmo período, o valor do ângulo Hue $\left(h^{\circ}=\tan ^{-1} b^{*} / a^{*}\right)$ diminuiu, indicando evolução da maturação.

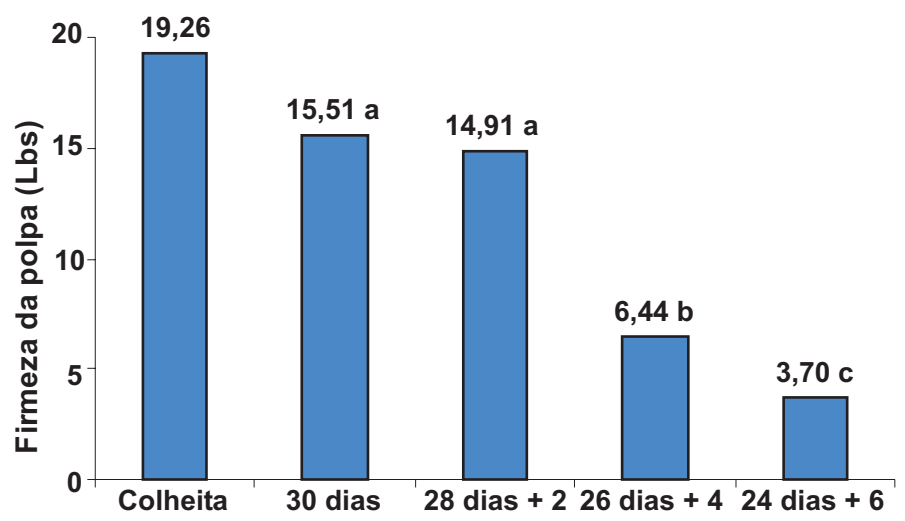

FIGURA 1 - Firmeza de polpa de pêras cv. Carick submetidas à refrigeração $\left(0 \pm 0,5^{\circ} \mathrm{C}\right.$ e $90-95 \%$ de UR), seguidas de armazenamento sob temperatura ambiente $\left(20 \pm 1^{\circ} \mathrm{C}\right.$ e 65 $70 \%$ de UR). Médias seguidas da mesma letra não diferem entre si pelo teste de Duncan $(\mathrm{p}<0,05)$.

TABELA 1 - Valores médios de L, a, b e ângulo Hue de pêras Carrick, submetidas à refrigeração $\left(0 \pm 0,5^{\circ} \mathrm{C}\right.$ e $90-95 \%$ de UR), seguidas de armazenamento sob temperatura ambiente $\left(20 \pm 1^{\circ} \mathrm{C}\right.$ e $65-70 \%$ de UR).

\begin{tabular}{lcccc}
\hline Tratamentos & $\mathrm{L}$ & $\mathrm{a}$ & $\mathrm{b}$ & ${ }^{\circ} \mathrm{h}$ \\
\hline T1(30+0 dia) & $41,6 \mathrm{~b}$ & $6,7 \mathrm{c}$ & $18,6 \mathrm{~b}$ & $70,1 \mathrm{a}$ \\
$\mathrm{T} 2(28+2$ dias $)$ & $41,7 \mathrm{~b}$ & $7,4 \mathrm{bc}$ & $19,3 \mathrm{~b}$ & $69,0 \mathrm{a}$ \\
$\mathrm{T} 3(26+4$ dias $)$ & $43,5 \mathrm{a}$ & $8,2 \mathrm{~b}$ & $21,6 \mathrm{a}$ & $69,2 \mathrm{a}$ \\
$\mathrm{T} 4(24+6$ dias $)$ & $43 \mathrm{a}$ & $10,2 \mathrm{a}$ & $21,5 \mathrm{a}$ & $64,6 \mathrm{~b}$ \\
\hline
\end{tabular}

Médias seguidas da mesma letra, na coluna, não diferem entre si, pelo teste Duncan $(\mathrm{p}<0,05)$.

A mudança da cor de fundo em pêssegos e nectarinas deve-se à degradação das clorofilas por clorofilases que, segundo Luchsinger e Walsh (1993), são estimuladas pela ação do etileno. Já a síntese de carotenóides e pigmentos que dão a coloração amarela à epiderme, é característico das frutas que estão fisiologicamente desenvolvidas. (Lelièvre et al, 1997, Girardi et al., 2000).

A acidez titulável diminuiu ligeiramente com o aumento do tempo sob temperatura ambiente, de modo que o menor valor foi registrado no tratamento 4 (Figura 2). Segundo Vangdal (1982), a acidez titulável apresenta mudanças não significativas no começo da maturação, declinando lentamente até o final do amadurecimento, embora estas mudanças não afetem o sabor. A pêra cv. Carrick apresentou uma ligeira oscilação, na colheita a porcentagem de ácido málico foi de $0,41 \%$ e no tratamento de 24 dias a $0^{\circ} \mathrm{C}$ seguido de 6 dias a $20^{\circ} \mathrm{C}$ foi de $0,32 \%$.

Os teores de sólidos solúveis totais aumentaram com o incremento do número de dias sob temperatura ambiente, com o maior valor ocorrendo no tratamento 4 (Figura 3).

Os dados obtidos indicaram uma evolução nos teores de sólidos solúveis $\left(11,7^{\circ} \mathrm{Brix}\right)$ na colheita até $13,87^{\circ} \mathrm{Brix}$ no tratamento 24 dias a $0^{\circ} \mathrm{C}$ mais 6 dias mantidas a $20^{\circ} \mathrm{C}$. A permanência em temperatura ambiente por dois ou quatro dias não proporcionou alterações significativas desses teores. Durante a maturação, o conteúdo de sólidos solúveis da pêra aumenta ligeiramente e depois decresce com a senescência (Vangdal, 1982). Valores de sólidos solúveis totais (11,8 a $18,6^{\circ}$ Brix) foram obtidos por Kappel et al. (1995) em experimento com cultivares distintas de pêra.

Segundo Nakasu e Leite (1990), a pêra cultivar Carrick é uma 


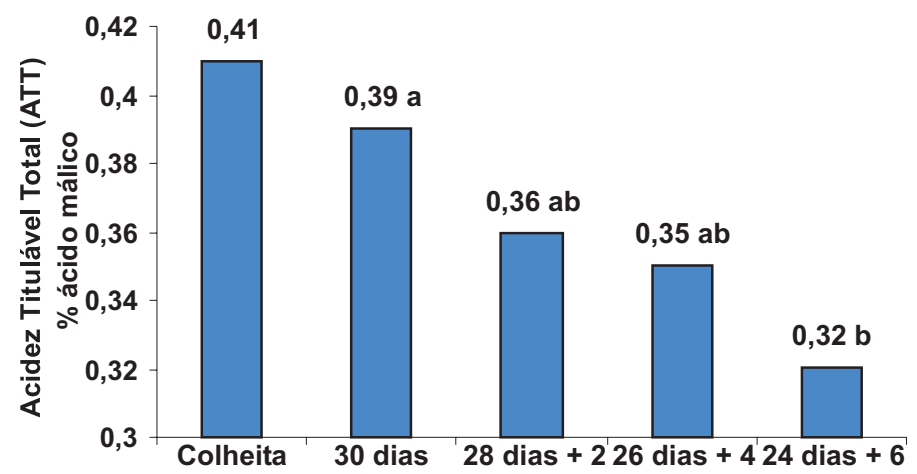

FIGURA 2 - Acidez titulável de pêras submetidas à refrigeração $\left(0 \pm 0,5^{\circ} \mathrm{C}\right.$ e $90-95 \%$ de UR), seguidas de armazenamento sob temperatura ambiente $\left(20 \pm 1^{\circ} \mathrm{C}\right.$ e $65-70 \%$ de UR). Médias seguidas da mesma letra não diferem entre si pelo teste de Duncan $(\mathrm{p}<0,05)$.

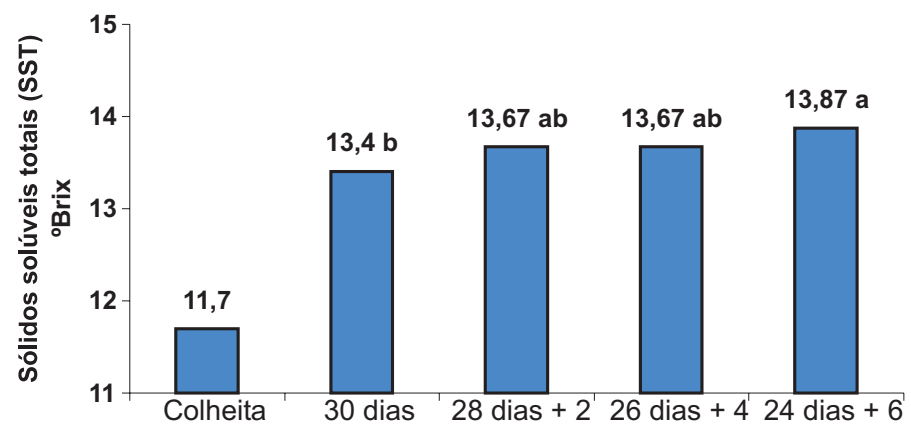

FIGURA 3 - Sólidos solúveis totais de pêras submetidas à refrigeração $\left(0 \pm 0,5^{\circ} \mathrm{C}\right.$ e $90-95 \%$ de UR), seguidas de armazenamento sob temperatura ambiente $\left(20 \pm 1^{\circ} \mathrm{C}\right.$ e $65-70 \%$ de UR). Médias seguidas da mesma letra não diferem entre si pelo teste de Duncan $(\mathrm{p}<0,05)$.

fruta de tamanho médio a grande, de forma oblonga-periforme, epiderme bronzeada com manchas avermelhadas. Sua polpa é de cor branca/ amarelada, medianamente macia, de suculência moderada, doce, com pouca acidez, leve aroma e adstringência. A descrição das características de aparência, sabor e de textura foram avaliadas, por uma equipe treinada de julgadores, que demonstraram diferenças significativas nas frutas dos diversos tratamentos (Tabela 2).

A avaliação da cor de fundo, nas frutas retiradas da câmara (30 dias) e imediatamente avaliadas mostraram o predomínio da coloração verde (Tabela 2). A partir de dois dias em temperatura ambiente, as frutas já apresentaram tonalidade de amarelo. A permanência das frutas em temperatura ambiente por 6 dias resultou no predomínio da cor amarela, como cor de fundo, indicando o estádio de maturação mais avançado. Segundo Seibert et al (2000), as pêras européias necessitam do armazenamento a frio associado a um período em temperatura ambiente para completar o amadurecimento.

A evolução da cor, com o predomínio do amarelo como cor de fundo, refletiu na avaliação da simulação de comercialização. O maior nível de aceitação no último tratamento, indicou a importância da cor, na escolha do produto, já que as frutas não apresentavam defeitos e/ou desidratação (Tabela 2), características importantes às diferentes classes de consumidores.

As frutas submetidas aos tratamentos 3 e 4 apresentaram doçura regular a moderada e, conseqüentemente, menores teores de acidez e uma maior intensidade de sabor característico da fruta, confirmando seu estádio de maturação mais avançado (Tabela 2).

Nos tratamentos 1 e 2, houve predomínio da acidez sobre a doçura, com as frutas classificadas como regularmente ácidas e ligeiramente doces (Tabela 2). Apresentaram ligeiro desenvolvimento do sabor característico, com leve predomínio de sabor estranho, indicado pelos julgadores como sabor "verde". A produção de compostos de aroma e sabor, conforme Cantillano (1987) é uma das principais mudanças que se verifica na maturação das pêras. Os resultados verificados neste trabalho, com as maiores médias de sabor nos dois últimos tratamentos, sendo o sabor classificado como de regular a moderado, concordando com a observação do autor. Provavelmente o sabor da pêra foi fortemente influenciado pelo conteúdo de açúcares da fruta.

O mesmo comportamento refletiu nas características de textura. Os tratamentos 1 e 2 apresentaram frutas com textura semi-rígida a rígida, segundo a classificação dada pela equipe sensorial (Tabela 2), correspondendo a valores de firmeza na faixa de 14 a 16 libras. As frutas em relação à suculência foram classificadas como ligeira a regular e regular arenosidade e adstringência, o que caracteriza frutas com maturidade fisiológica, mas ainda com maturação de consumo incompleta.

As frutas dos tratamentos 3 e 4 caracterizaram-se por apresentar: polpa macia (tratamento 3), muito macia (tratamento 4); moderada suculência; ligeira arenosidade e sem adstringência (tabela 2). As frutas dos tratamentos 3 e 4 atingiram, portanto, a maturação de consumo. Segundo Faoro et al. (1999b), as pêras japonesas apresentam grãos arenosos. Neste trabalho, com pêras européias, a arenosidade foi percebida pelos julgadores com mais intensidade nos tratamentos 1 e 2, enquanto nos demais, a arenosidade da polpa foi classificada como ligeira, tendendo à sensação de amanteigada, termo amplamente utilizado por Faoro (1999a), na caracterização das pêras tipo européia.

A qualidade, no sentido amplo, reflete, portanto, os valores

TABELA 2 - Valores médios obtidos na avaliação sensorial de pêras cv. Carrick submetidas à refrigeração ( $0 \pm 0,5^{\circ} \mathrm{Ce} 90-95 \%$ de UR), seguidas de armazenamento sob temperatura ambiente $\left(20 \pm 1^{\circ} \mathrm{C}\right.$ e $65-70 \%$ de UR).

\begin{tabular}{|c|c|c|c|c|}
\hline Variáveis & $\begin{array}{ccc}\text { T } 1 \\
30 \operatorname{dias} \text { a } 0 & C\end{array}$ & $\begin{array}{c}\text { T } 2 \\
28 d i a s \text { a } 0^{\circ} \mathrm{C}+2 \text { dias a } 20 \mathrm{C}\end{array}$ & $\begin{array}{c}\text { T } 3 \\
26 \text { dias a } 0^{\circ} \mathrm{C}+4 \text { dias a } 20 \mathrm{C}\end{array}$ & $\begin{array}{c}\text { T } 4 \\
24 \text { dias a } 0^{\circ} \mathrm{C}+6 \text { dias a } 20 \mathrm{C}\end{array}$ \\
\hline Cor de fundo & $2,60 \mathrm{D}^{*}$ & $4,13 \mathrm{C}$ & $4,97 \mathrm{~B}$ & $7,15 \mathrm{~A}$ \\
\hline Defeitos & $0,76 \mathrm{D}$ & $1,12 \mathrm{C}$ & $1,55 \mathrm{~B}$ & $1,91 \mathrm{~A}$ \\
\hline Desidratação & $0,06 \mathrm{~A}$ & $0,08 \mathrm{~A}$ & $0,15 \mathrm{~A}$ & $0,16 \mathrm{~A}$ \\
\hline Comercialização & $6,66 \mathrm{C}$ & $6,98 \mathrm{BC}$ & $7,27 \mathrm{~B}$ & $8,02 \mathrm{~A}$ \\
\hline Doçura & $1,49 \mathrm{C}$ & $1,94 \mathrm{C}$ & $5,08 \mathrm{~B}$ & $6,45 \mathrm{~A}$ \\
\hline Acidez & $5,37 \mathrm{~A}$ & $4,78 \mathrm{~B}$ & $2,45 \mathrm{C}$ & $1,87 \mathrm{D}$ \\
\hline Sabor & $2,82 \mathrm{C}$ & $3,87 \mathrm{C}$ & $5,56 \mathrm{~B}$ & $7,93 \mathrm{~A}$ \\
\hline Sabor Estranho & $1,73 \mathrm{~B}$ & $0,24 \mathrm{~B}$ & $0,12 \mathrm{~B}$ & $0,95 \mathrm{~A}$ \\
\hline Firmeza de polpa & $8,11 \mathrm{~A}$ & $7,81 \mathrm{AB}$ & $3,64 \mathrm{C}$ & $1,81 \mathrm{D}$ \\
\hline Suculência & $3,89 \mathrm{C}$ & $4,30 \mathrm{C}$ & $6,33 \mathrm{~B}$ & $6,95 \mathrm{~A}$ \\
\hline Arenosidade & $5,19 \mathrm{~A}$ & $4,83 \mathrm{AB}$ & $3,82 \mathrm{C}$ & $3,28 \mathrm{D}$ \\
\hline Adstringência & $4,77 \mathrm{~A}$ & $4,12 \mathrm{~B}$ & $1,07 \mathrm{C}$ & $0,53 \mathrm{D}$ \\
\hline Qualidade Geral & $2,63 \mathrm{D}$ & $3,66 \mathrm{C}$ & $7,17 \mathrm{AB}$ & $7,61 \mathrm{~A}$ \\
\hline
\end{tabular}

* Letras distintas na horizontal indicam diferenças significativas pelo teste de Tukey em nível de $5 \%$ de probabilidade. 
atribuídos às características de sabor e textura, onde se destacaram os tratamentos 3 e 4 classificados como bom a ótimo, enquanto os demais foram classificados como os de menor qualidade (Tabela 2).

Vangdal (1982) afirma que o sabor das pêras é fortemente influenciado pelo conteúdo de sólidos solúveis totais da fruta, o que encontra concordância com o aumento da relação SST/AT (Figura 4).

Segundo Chitarra (1997), os sólidos solúveis totais e a acidez titulável são importantes características de qualidade do sabor. Enquanto o teor de sólidos solúveis aumenta durante o amadurecimento, a acidez diminui, propiciando uma variação da relação sólidos/acidez entre 15 a 25, índice considerado ótimo para a colheita ou consumo de pêssegos e ameixas. Neste trabalho, foram obtidos valores baixos de acidez que propiciaram uma variação da relação SST/AT entre 34 a 44. No caso de pêra cv. Carrik, valores em torno de 39 são considerados os mais adequados para consumo, o que foi confirmado pelos dados obtidos principalmente em relação ao sabor e à qualidade geral.

As pêras praticamente não apresentaram sinais de podridão, nos diferentes tratamentos estudados, durante todo o tempo de armazenamento.

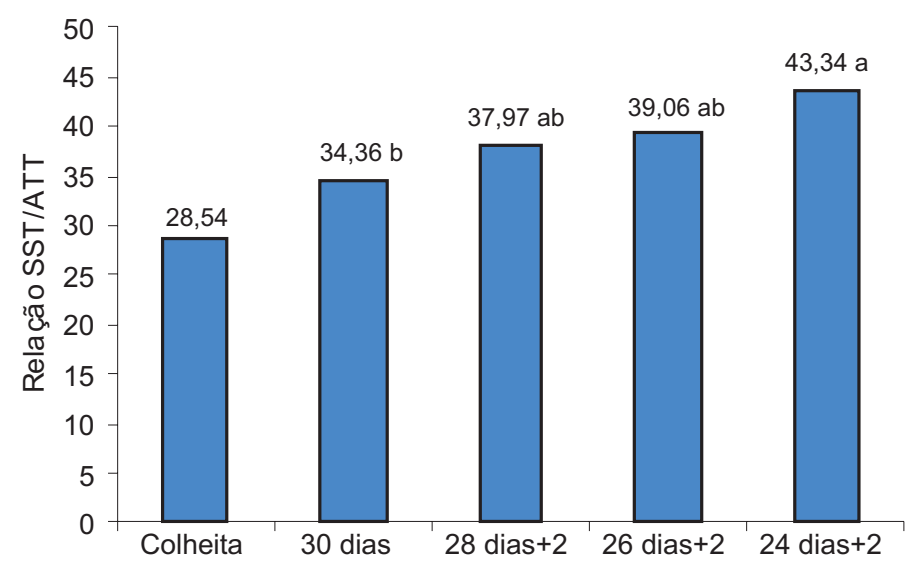

FIGURA 4 - Relação SST/AT de pêras submetidas à refrigeração $\left(0 \pm 0,5^{\circ} \mathrm{C}\right.$ e $90-95 \%$ de UR), seguidas de armazenamento sob temperatura ambiente $\left(20 \pm 1^{\circ} \mathrm{C}\right.$ e $65-70 \%$ de UR). Médias seguidas da mesma letra não diferem entre si pelo teste de Duncan $(\mathrm{p}<0,05)$.

\section{CONCLUSÕES}

Pêras da cv. Carrick armazenadas sob refrigeração pelos períodos de 24 e 26 dias, e amadurecidas por 4 e 6 dias sob temperatura de $20^{\circ} \mathrm{C}$ tiveram melhor qualidade de comercialização e consumo.

\section{REFERÊNCIAS BIBLIOGRÁFICAS}

CANTILLANO, R.F.F. Fisiologia e manejo de pós-colheita em pêras européias e asiáticas. 1987, p.1-13 (Comunicado Técnico, 55).

CHITARRA, A.B. Qualidade, colheita e manuseio pós-colheita de frutos do pessegueiro e da ameixeira. Informe Agropecuário. Belo
Horizonte, v.18, n.189, p.68-74, 1997.

FAORO, I.D.; HENTSCHKE,R.; SHIBA S. Pêras comerciais para as regiões mais frias de Santa Catarina. Agropecuária Catarinense, Florianópolis, v.12, n.2, p.5-6. 1999a.

FAORO, I.D.; HENTSCHKE, R.; SHIBA, S. Situação mundial e brasileira da cultura da pereira. Agropecuária Catarinense, Florianópolis, v.12, n.3, p.48-9, 1999b.

GIRARDI, C.L.; ROMBALDI, C.V.; PARUSSOLO, A.; DANIELI, R. Manejo pós-colheita de pêssegos cultivar Chiripá. Bento Gonçalves: Embrapa Uva e Vinho, 2000. 36p. (Circular Técnica, 28).

JOÃO, P.L.; ROSA, J.I.; FERRI, V.C.; MARTINELLO, M.D. Levantamento da fruticultura Comercial do Rio Grande do Sul. EMATER RS. Realidade Rural, Porto Alegre, v.28, p.17, 2002.

KAPPEL, K.; FISHER-FLEMING, R.; HOGUE, E.J. Ideal pear sensory attributes and fruit characteristics. HortScience, Alexandria, v.30, n.5, p.988-993, 1995.

LAWLESS H. T.; HAYMANN H. Sensory evolution of food. New York: CHAPMAN e RALL, 1998. 827p.

LELIĖVE, J.M.; LATCHÉ. A.; JONES, B; BOUZAYEN,M.;PECH,J.C. Ethylene and fruit ripening. Physiologia Plantarum, Copenhagen, v.101, p.727-739. 1997

LUCHSINGER, L.E.; WALSH, C.S Changes in ethylene rate and ground color in peaches (cv. Redhaven and Marqueen) and nectarines (cv. Fantasia) during maturation and ripening. Acta Horticulturae. Wageningen, v.343, p.70-72. 1993.

INSTITUTO ADOLFO LÜTZ. Normas analíticas do Instituto Adolfo Lutz: métodos químicos para análise de alimentos. 3. ed. São Paulo, 1985.533p.

MADAIL, J.C.M.; REICHERT,L.J. Aspectos econômicos das principais frutas de clima temperado: pêssego, nectarina, maçã, ameixa, pêra e morango. Pelotas: Embrapa Clima Temperado, 2002. (Comunicado Técnico). no prelo.

NAKASU, B.H.; LEITE, D.L. Indicação de porta - enxerto e cultivares de pereira para o sul do Brasil. Hortisul, Pelotas, v.1, n.2, p.20-24, 1990.

PORRIT, S.W. The effect of temperature on postharvest physiology and storage life pears. Canadian Journal Plant Science, Otawa, v.44,p.568-577, 1964.

RIBEIRO, P.A.; BRIGUENTI, E.; BERNARDI, J. Comportamento de algumas cultivares de pereira (Pyrus communis L.) e suas características nas condições do planalto catarinense. Florianópolis: EMPASC, 1991. 53p.

SEIBERT, E.; BARRADAS, C.I.N.; ARAUJO, P.J.; BENDER, R.J. Efeito do ethephon e da frigoconservação na maturação de pêras cv. Packham‘s Triumph. Pesquisa Agropecuária Brasileira, Brasília, v.35, n.1, p.55-62, 2000.

VANGDAL, E. Eating quality of pears. Acta Agriculture Scandinavica, Norway, v.32, p.135-139, 1982.

ZECCA, A.G.D. Micro-enxerto, enxertia de calo e enxertia de micro-estaca sobre calo in vitro, como método de determinação de incompatibilidade de pereira (Pyruis spp.) sobre marmeleiro (Cynodia oblonga). 1995. 110f. Dissertação (Mestrado) Universidade Federal de Pelotas, Pelotas, 1995. 